\title{
COMO SE PRODUZ DESASTRES?: O PROCESSO DE LICENCIAMENTO DA BARRAGEM DE REJEITOS DA HYDRO ALUNORTE, EM BARCARENA, PARÁ
}

\author{
RODRIGUES, Jondison Cardoso ${ }^{1}$ \\ HAZEU, Marcel Theodoor ${ }^{2}$ \\ NASCIMENTO, Sabrina Mesquita do ${ }^{2}$
}

\begin{abstract}
RESUMO: O artigo analisa o processo de licenciamento da barragem de rejeitos da Hydro Alunorte, em Barcarena, no estado do Pará e como este contribui na produção de riscos e desastres socioambientais. O procedimento metodológico se pautou: 1) na análise documental do processo de licenciamento; 2) na compreensão da base legal; e, 3) registros "não-oficiais" (relatos, narrativas e diálogos com lideranças). A abordagem teóricometodológico é pautada na Sociologia dos Desastres. O estudo constatou inúmeras irregularidades no processo de licenciamento, das três grandes expansões produtivas. Destacamos no artigo: 1) a dispensa de Estudos de Impacto Ambiental; 2) a não-realização de fiscalizações e monitoramento das barragens de rejeitos; 3) a não-observância das bases legais, como a Política Nacional de Segurança de Barragens; 4) ações de natureza antidemocrática/não participativa e com violação de direitos humanos. Há um discurso afinado da empresa e do Estado, pautado no gerenciamento social e ambiental compartilhado, por exemplo, ao negar o transbordamento da barragem (em 2018) e de "culpabilização da chuva". Avalia-se que o licenciamento ambiental não constitui um elemento técnico crítico e sim componente político e "contribuidor" de desastres e crimes ambientais, assim como tais irregularidades contribuem diretamente para os consecutivos desastres ocorridos nos últimos anos.
\end{abstract}

Palavras-chave: Desastres socioambientais. Política Nacional de Segurança de Barragens. Crimes ambientais. Licenciamento ambiental.

\section{HOW DOES DISASTERS PRODUCE: THE LICENSING PROCESS OF HYDRO ALUNORTE REJECTION DAM, IN BARCARENA, PARÁ}

SUMMARY: This article analyze the licensing process of the Hydro Alunorte mining dam in Barcarena, state of Pará, and how it contributes to the production of socioenvironmental risks and disasters. The methodological procedure was based on: 1) the documentary analysis of the licensing process; 2) understanding the legal basis; and, 3) "unofficial" records (reports, narratives and dialogues with leaders). The theoretical-methodological approach is based on Sociology of Disasters. The study found several irregularities in the licensing process of the three large productive expansions. We emphasize in the article: 1) the exemption of Environmental Impact Studies; 2) failure to carry out monitoring and monitoring of mining dams; 3) non-compliance with legal bases, such as the National Policy on Dam Safety; 4) antidemocratic/non-participatory actions and violations of human rights. There is a refined discourse by the company and the state, based on shared social and environmental management, for example, by denying the overflow of the dam (in 2018) and by "blaming the rain." We believe that environmental licensing is not a critical technical element but a political and "contributor" to environmental disasters and crimes, just as such irregularities contributed directly to the consecutive disasters that have occurred in recent years.

Keywords: socioenvironmental risks. National Policy on Dam Safety. Environmental crimes. environmental licensing

\section{INTRODUÇÃO}

Desde o início da década de 2000 houve um aumento significativo do extrativismo mineral a céu aberto no continente latino-americano, e, particularmente no sul-americano (ZHOURI;BOLADOS;

\footnotetext{
${ }^{1}$ Universidade Federal do Amapá (UNIFAP)

${ }^{2}$ Universidade Federal do Pará (UFPA)
} 
CASTRO, 2016). Segundo Wanderley (2017), esse aumento está associado ao boom de commodities, a partir do crescimento da demanda da economia Chinesa e da crescente financeirização do setor de commodities, especialmente por meio da especulação no mercado futuro (MILANEZ, 2017a; GONÇALVES; MILANEZ; WANDERLEY, 2018). Cabe destacar que a China foi responsável por 18\% em 2001, e passou a importar 67\% do minério de ferro mundial em 2014 (WANDERLEY, 2017).

Para Wanderley (2017), a importação global de minério de ferro passou de 500 milhões de toneladas em 2001 para 1.394 milhões em 2014 (elevação de 178\%) e no período entre 2001 e 2014, a oferta de ferro, mais que duplicou, passando de pouco menos de 1,06 bilhão de t/ano para volume superior a 3,4 bilhões. Isso aponta que a indústria extrativa mineral, apesar da sua desaceleração, tem crescido tanto em volumes extraídos quanto em ganhos financeiros, com a abertura ou expansão de novas minas e refinarias. Em relação ao alumínio, por exemplo, o crescimento em termos de fluxos econômicos exportados no Brasil subiu de 129.033,4 toneladas no ano de 2000 para 930.206,6 toneladas, em 2017 (MICES, 2018).

Em 2007, só no Pará, pelo porto de Vila do Conde (no município de Barcarena), exportou-se 435.699 toneladas de alumínio e 3.238.742 toneladas de alumina, e em 2017, 5.014.443,00 toneladas de alumina e 208.906 toneladas de alumínio (CDP, 2019; ANTAQ, 2019). E todo esse fluxo econômico (de exportação de alumínio) é de responsabilidade da empresa Hydro Alunorte.

De acordo com Coelho et al (2017), o crescimento da extração de minérios e produção minerometalúrgico e a consequente multiplicação das barragens ao longo do último século ocorreram na mesma proporção dos vazamentos e rompimentos de reservatórios de resíduos em diversos do mundo. O rompimento de barragem de rejeitos no Brasil mais noticiado foi da empresa Samarco Mineração S.A, em novembro de 2015, no município de Mariana, em Minas Gerais, seguido do desastre em 2019 de Brumadinho.

Destacam-se também os consecutivos vazamentos de lama/rejeitos dos Depósitos de Resíduos Sólidos (ou também barragem de rejeitos ${ }^{3}$ ), da companhia Hydro Alunorte, em Barcarena-PA, que tem seus pontos mais dramáticos os desastres ocorridos em abril de 2009 e em fevereiro de 2018. Todos esses rompimentos em intervalos muito próximos e consecutivos. Junto a isso o objetivo do artigo foi analisar criticamente o processo de licenciamento da barragem de rejeitos da Hydro Alunorte, em Barcarena, no estado do Pará, no sentido de responder como ele contribuiu com a constante produção de riscos e desastres ao longo dos últimos anos.

\section{METODOLOGIA}

Para responder as questões alavancadas, realizaram-se: 1) uma análise documental do processo de licenciamento; 2) um mergulho na base legal nacional sobre proteção civil e segurança de barragens; e, 3) uma leitura dos registros "não-oficiais" de denúncias sobre a eminência dos desastres em Barcarena.

\footnotetext{
${ }^{3}$ Segundo Art. $1^{\mathrm{o}}$ da Lei que estabelece a Política Nacional de Segurança de Barragens (PNSB), mas precisamente no parágrafo único, barragens destinadas à acumulação de água para quaisquer usos, à disposição final ou temporária de rejeitos e à acumulação de resíduos industriais que apresentem pelo menos uma das seguintes características: i altura do maciço, contada do ponto mais baixo da fundação à crista, maior ou igual a 15m; II - capacidade total do reservatório maior ou igual a $3.000 .000 \mathrm{~m}^{3}$; III - reservatório que contenha resíduos perigosos conforme normas técnicas aplicáveis. No Art. $2^{-}$PNSB, barragem é qualquer estrutura em um curso permanente ou temporário de água para fins de contenção ou acumulação de substâncias líquidas ou de misturas de líquidos e sólidos, compreendendo o barramento e as estruturas associadas. Essa demarcação é importante para qualquer tipo de neologismo e novas nomenclaturas eufemística, por exemplo, bacias e depósitos de resíduos sólidos.
}

Nucleus,v.16,n.2,out.2019 
$\mathrm{Na}$ análise documental do processo de licenciamento da barragem de rejeitos da Hydro Alunorte, constam: o memorial descritivo da expansão do DRS 2; os Programas e planos da Hydro Alunorte; as Licenças Ambientais de instalação e operação e suas respectivas condicionantes; o parecer técnico da Secretaria de Estado de Meio Ambiente e Sustentabilidade (SEMAS) de concessão da LI: o parecer Técnico emitido pela SEMAS, PT $\mathrm{N}^{\circ}$ 6296/GEND/CLA/DILAP/2013 e $\quad$ PT $\quad \mathrm{N}^{\circ}$ 6296/GEND/CLA/DILAP/2014. Ainda examinamos os site de notícias da Hydro Alunorte e o Anual Report 2017, além do site da SEMAS (Secretaria de Meio Ambiente e Sustentabilidade) relativo a trabalhos em Barcarena, com notícias, auto de infrações, notificações, termo de embargo e o Relatório de Fiscalização REF-1-s/18-03-00007.

Quanto à base legal nacional de proteção civil e segurança de barragens, debatemos: i) a Lei $n^{\circ}$ 12.334/2010, que estabelece a Política Nacional de Segurança de Barragens; ii) a Lei $n^{\circ} 12.608 / 2012$, que institui a Política Nacional de Proteção e Defesa Civil - PNPDEC; e, iii) o Decreto $N^{\circ} 4.085 / 2002$ Convenção $\mathrm{n}^{\mathrm{0}} 174$ da OIT e a iv) a Recomendação $\mathrm{n}^{\circ}$ 181, que versa sobre a Prevenção de Acidentes Industriais Maiores.

Por fim, entre os registros "não-oficiais" foram coletadas: i) relatos, narrativas e diálogos com lideranças, durante e após o I e II Seminários Desastres da Mineração, ocorridos respectivamente, em Belém e Barcarena; e, ii) Diálogos com o Movimento Barcarena Livre ${ }^{4}$, com pesquisa de pesquisa de campo. A análise se pauta no diálogo entre a Sociologia dos Desastres ${ }^{5}$ (VALÊNCIO, 2011, 2014a, 2014b, 2015, 2017) e a análise crítica da cadeia minero-metalúrgica, seus impactos complexos e a simplificação da legislação do extrativismo mineral (MILANEZ, 2017a, 2017b; MILANEZ; SANTOS, 2014, MILANEZ; COELHO; WANDERLEY, 2017; SANTOS; MILANEZ, 2018; MILANEZ, SANTOS; PINTO, 2018).

\section{RESULTADO E DISCUSSÃO}

\section{A HYDRO ALUNORTE E O LICENCIAMENTO DA BARRAGEM DE REJEITOS}

A fábrica Alunorte em Barcarena, propriedade da Hydro, é considerada a maior refinaria de alumina do mundo, além de deter toda a tecnologia - técnicas, científicas, políticas e econômicas - de extração, produção e distribuição do minério. Isso envolve o domínio completo da cadeia produtiva do alumínio, desde a lavra da bauxita, o refinamento da alumina e sua transformação em alumínio primário e produtos laminados, até a sua exportação.

A Hydro é uma empresa multinacional norueguesa, com 2,69 bilhões de ações emitidas, sendo que o estado norueguês possui 34,7\% destas ações. Entre os demais acionistas, destacam-se os investidores:

\footnotetext{
${ }^{4}$ O Movimento Barcarena Livre surge a partir das articulações entre moradores de comunidades tradicionais, organizações de trabalhadores de Barcarena, pesquisadores e profissionais organizadores dos Seminários "Desastres da Mineração" realizados em Belém e Barcarena no ano de 2016. Tem como objetivo principal lutar por uma Barcarena livre de poluição, exploração, repressão e violações de direitos humanos. Produz o Barcarena Livre Informa como instrumento de resistência e contra-informação para colaborar nas lutas pelo direito legítimo dos povos, comunidades e trabalhadores de serem respeitados(as) (MOVIMENTO BARCARENA LIVRE, 2016).

${ }^{5}$ Trata-se de um tipo de crise social espacialmente delimitada, cuja deflagração, contudo, não se deve apenas a um acontecimento físico pontual naquele local, mas a processos e interações sociais mais amplos e tidos como normais em diferentes escalas da vida social (isto é, transcendem ao lugar afetado). Desastres são, ainda, caracterizados pela sujeição de uma dada coletividade a um nível incomum de sofrimento coletivo, fazendo seus sobreviventes prosseguirem nos momentos seguintes com os parcos recursos sobrantes. Quando chegam a adquirir proporções catastróficas e relacionam-se a megaempreendimentos (na fase de implantação ou de operação), os desastres manifestam-se como uma tessitura multifacetada e sinérgica de riscos concretizados, sejam esses previamente conhecidos, desconhecidos, subestimados ou escamoteados (VALENCIO, 2017, p. 170).
} 
State Street Bank and Trust Comp (Estados Unidos), Clearstream Banking (Luxemburgo), HSBC Bank (Grã-Bretanha), J. P. Morgan Bank Luxembourg (Luxemburgo), Banque Pictet e Cie (Suíça), J.P Morgan Chase Bank (Grã-Bretanha) e Euroclear Bank (Bélgica).

Com base em dados de 2017, uma média de 14\% da produção da Hydro Alunorte (de Barcarena) é destinada ao mercado interno brasileiro e os outros $86 \%$ à exportação. Atualmente, a empresa exporta principalmente para os mercados do Canadá, Noruega, Islândia, Rússia, Estados Unidos, Emirados Árabes Unidos, Letônia, Japão e México (SEDEME, 2019). Possuem bases e escritórios nas cidades de Belém, Itu, Barcarena, Paragominas, Rio de Janeiro, Santo André, Trombetas, São Paulo e Tubarão.

Em 2010, a Hydro comprou os ativos referentes à produção de bauxita, alumina e alumínio da Vale (por 4,9 bilhões de dólares), que receberia 1,1 bilhão de dólares em dinheiro e uma participação de 21,6\% na Hydro, avaliada em 3,1 bilhões de dólares (SOLSVIK; MOSKWA, 2019). A aquisição incluiu as operações de mineração de bauxita, em Paragominas, a participação majoritária na maior refinaria de alumina do mundo, Alunorte, e a participação de $51 \%$ na principal empresa de alumínio do Brasil, a Albras.

Por fim, em 2013, a Hydro comprou 407.122.241 de ações da Vale, por US\$ 1,656 bilhão. E, dessa forma, a participação de 21,6\% da Vale caiu para 2,0 \% das ações autorizadas e emitidas pela Hydro. Nesse mesmo ano, realizou a fusão com a SAPA Aluminium, por um valor equivalente a U\$S 3,381 bilhões. Nesse cenário, houve a expansão das atividades produtivas da Hydro Alunorte em Barcarena, como também das suas barragens de rejeitos.

\section{BARRAGENS E EXPANSÕES DA HYDRO ALUNORTE}

Segundo Souza Junior, Moreira e Heineck (2018), no Brasil há 839 barragens de rejeitos registradas, sendo a maioria $(66 \%)$ de pequeno porte (com volume total de reservatório inferior a $0,5 \mathrm{hm}^{3}$ ) e concentradas no estado de Minas Gerais (43,5\%). Ainda segundo os autores, no que tange aos critérios de riscos, a maioria (aproximadamente 77\%) encontra-se em categoria de risco baixo. Quanto ao Dano Potencial Associado (DPA), 56,5\% encontram-se em nível baixo, porém 26,58\% possuem DPA elevado.

Porém, o Relatório de Segurança de Barragens 2017, da Agência Nacional de Águas (ANA), assinala 753 barragens de contenção de resíduos industriais e 790 de rejeitos de mineração ${ }^{6}$ (ANA, 2018). Já a Gerência de Segurança de Barragens de Mineração, da Agência Nacional de Mineração (ANM), no Cadastro Nacional de Barragens de Mineração, afirma que há 769 barragens (com base em atualizações realizadas em janeiro de 2019) (ANM, 2019).

Segundo ANM o estado do Pará possui as seguintes barragens (Tabela 1):

\footnotetext{
${ }^{6}$ Segundo a ANA (2018), os empreendedores com elevado número de barragens são a VALE S/A (175 Barragens), CMPC Celulose Riograndense Ltda (174 barragens), SABESP (130 barragens), CODEVASF (116 barragens), COMPESA (88 barragens) e SRH/COGERH/CE (84 barragens).
} 
Tabela 1: Quantidade e características de barragens inseridas na $\mathrm{PNSB}^{7}$ no estado do Pará

\begin{tabular}{lccc}
\hline Município & $\begin{array}{c}\text { Quantidade de } \\
\text { barragem(s) }\end{array}$ & Empresa & Altura (m) \\
\hline Parauapebas & 11 & Vale & $7,5-34$ \\
Paragominas & 4 & Mineração Paragominas/Imerys & $13-37$ \\
Marabá & 7 & Salobo Metais/Vale & $11-63$ \\
Ipixuna do Pará & 3 & Pará Pigmentos/Imerys & $8-13$ \\
Itaituba & 3 & Serabi Mineração & $7-14,5$ \\
Barcarena & 11 & Imerys & $3-13,5$ \\
Juruti & 4 & Alcoa & $11,5-24$ \\
Curionópolis & 1 & Avb Mineração & 11 \\
Almeirim & 1 & Cadam/KaMin & 35 \\
Canaã dos Carajás & 1 & Vale & 42,10 \\
Oriximiná & 23 & Mineração Rio do Norte & $8-20$ \\
\hline
\end{tabular}

Fonte: ANM (2019)

* Destacamos aqui a altura menor e altura maior da barragem. Para saber em detalhes vide ANM (2019).

O estado do Pará possui, portanto, 69 barragens inseridas na PNSB e 35 não inscritas. A Hydro Alunorte possui duas barragens de rejeitos (a DRS1 e a DRS 2/embargada), porém a empresa se recusa a tratar o local de rejeitos como barragem e o denomina como bacia ou depósito, e, portanto não estão mencionados na listagem da ANM acima. Nos discursos e no próprio processo de licenciamento ambiental as áreas são tratadas como Depósitos de Rejeitos Sólidos (DRS).

Esse processo de autodefinição realizado pela empresa inicia-se com a inauguração da Alunorte em 1995. Segundo o relatório anual da Alunorte de 2009 (ano do grande desastre ambiental provocado pelo transbordo da barragem de rejeitos), a primeira célula do DRS foi iniciada em 1995, em uma área de aproximadamente 15 ha. Em 2009, a "barragem" já ocupava cerca de 130 ha. Esses rejeitos quando transbordaram atingiram as nascentes e percurso do rio (o rio Mucurupi), da qual afetaram diretamente a vida de quase 100 famílias que moram na área e indiretamente milhares de outras famílias que dependem dos rios. Essas famílias ficaram sem água para beber, para o uso doméstico e ainda foram impedidos de pescar para se alimentar; além disso, os poços utilizados pelas famílias atingidas foram poluídos por metais pesados.

Dadas às especificidades quanto aos riscos que representam, e a depender das dimensões de cada expansão produtiva, tanto o aumento nas áreas de barragens quanto à abertura de novos espaços deveriam ser acompanhados de um rigoroso processo de licenciamento ambiental. No entanto, o que se observou no caso dos Depósitos de Resíduos Sólidos 1 e 2 da Hydro Alunorte, é que o aumento da área destinada aos rejeitos da mineração (Figura 2) ocorreu sem o acompanhamento de um licenciamento específico.

Uma das grandes irregularidades notadas aqui é que, após o vazamento de 2009, foi solicitada a renovação de licença para “expansão de depósito de rejeitos”, em $2013^{8}$. Porém, como notamos nas imagens a seguir, trata-se efetivamente da abertura de uma nova estrutura e não de uma expansão, por isso a renovação de licença não seria o procedimento a ser aplicado, já que não se tratava da operação de uma mesma estrutura (DRS1) e sim da abertura de nova área para rejeitos (DRS2); ou seja, um novo licenciamento deveria ter sido iniciado.

Outro destaque é que a Hydro "aproveitou" a própria área em que ocorrera o vazamento de 2009 para expandir o DRS1 enquanto planeja a instalação de uma nova estrutura. Em resumo, tanto as

\footnotetext{
${ }^{7}$ Segundo a ANM (2019), para se inserir e/ou se cadastrar na PNSB é preciso alguns critérios: i) maior ou igual a 15 $\mathrm{m}$; ii) possuir um volume maior ou igual a 3 milhões $\mathrm{de}^{3}$; iii) possuir resíduo perigoso; iv) possuir dano potencial associado médio ou alto.

${ }^{8}$ Processo n. 2013/0000016617 para o Projeto Depósitos de Resíduos Sólidos 2.
}

Nucleus,v.16,n.2,out.2019 
expansões observadas ao longo dos anos no DRS1 quanto à abertura do DRS2 dispensaram a apresentação de EIA/RIMA e obtiveram licenças de instalação e operação como meros procedimentos administrativos.

Figura 1: Quadro de imagens acerca evolução temporal das expansões da barragem de rejeitos da Hydro Alunorte
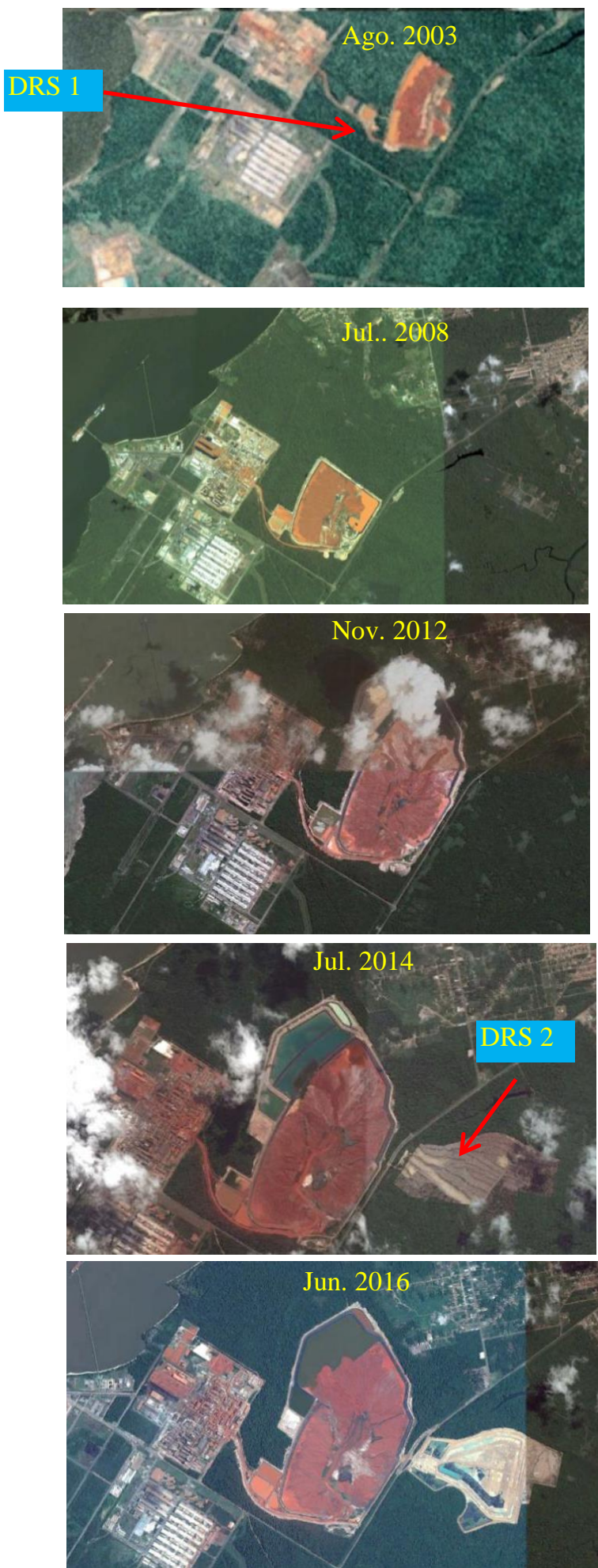
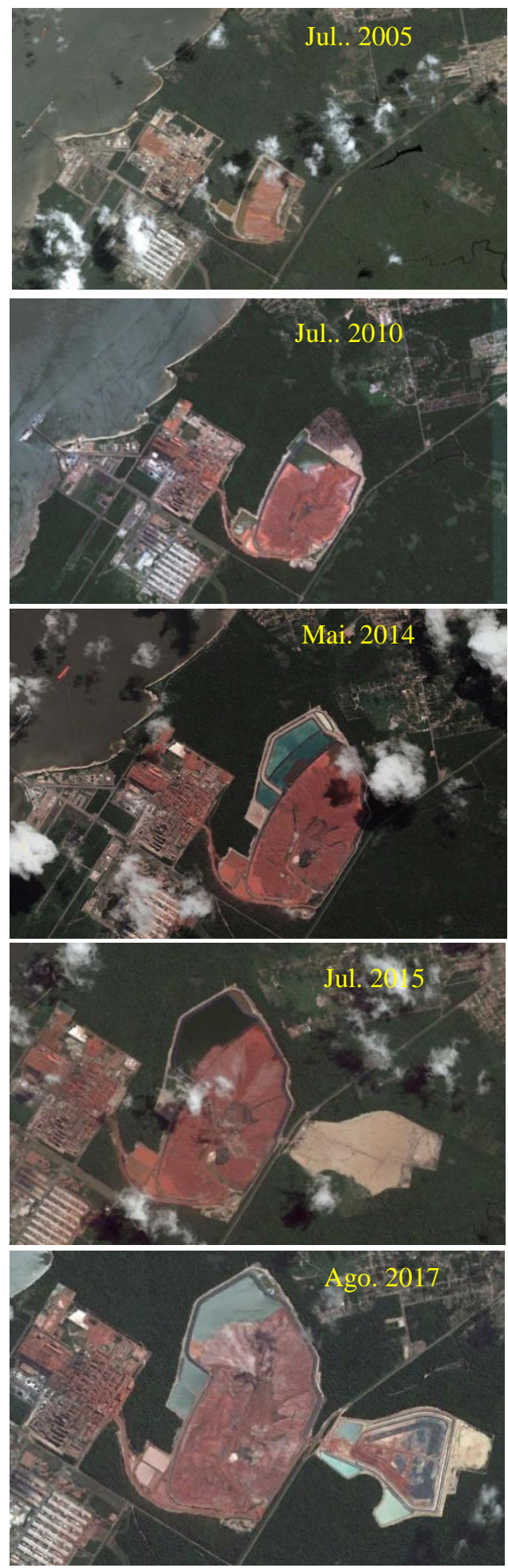

Fonte: Elaborado a partir do Google Earth Pro 


\section{O PROBLEMA DAS FISCALIZAÇÕES: A FALTA DE CONTROLE SOBRE AS ATIVIDADES PRODUTIVAS DA HYDRO}

As sucessivas "expansões" nas áreas de rejeitos da Hydro não foram acompanhadas de processos de fiscalização por parte da SEMAS, seja na concessão da licença de instalação em 2010 (que também acontecia expansão) seja na concessão da licença em 2013. Tal afirmação é amparada no Relatório de Segurança de Barragens 2017 (publicação ocorrida em novembro de 2018), que aduz que não houve nenhuma fiscalização (e também nenhum "acidente" ou desastre) ou "anomalia".

No caso do licenciamento ambiental da nova barragem de rejeitos (a DRS 2), houve apenas uma vistoria técnica da SEMAS, realizada no período de 14 a 17 de maio de 2013, que afirma que "além da área de supressão vegetal para DRS2 e seu entorno, a equipe técnica visitou as instalações da fábrica a fim de compreender o processo produtivo" (Parecer Técnico emitido pela SEMAS, PT $\mathrm{N}^{\circ}$ 6296/GEND/CLA/DILAP/2013).

Já a "visita técnica", da Diretoria de Licenciamento Ambiental de Atividades Poluidoras (DILAP/SEMAS), realizada no dia 24/06/2014, deu-se no contexto da implantação de dutos para deslocamento dos fluxos de bauxita até barragem de rejeitos (a DRS 2), passando pela PA-481 (Parecer Técnico, PT No 6296/GEND/CLA/DILAP/2014). Essa estrutura (dutos) que passava pela PA-481 também "possuía autorização" para a instalação, de acordo com a SEMAS.

Essa "constatação" é configuração de um Estado que se apresenta por meio de ação-presença "de governar à distância e garantir a governabilidade do setor mineral ao delegar algumas de suas responsabilidades" (ST-LAURENT; BILLON, 2015, p. 592). Além disso, configura-se também o processo de flexibilização do licenciamento ambiental (MILANEZ, 2017b; MILANEZ; COELHO; WANDERLEY, 2017), o que significa consequentemente licenças que tem como fim a degradação (RODRIGUES, 2016). No caso de Barcarena, e dialogando com Hazeu e Rodrigues (2019) seria a naturalização de dores, sofrimentos e doenças, e "regimes de permissão", concedidos pelo Estado, para poluir, amputar, empobrecer e "matar" lentamente, com metais pesados, populações mais vulneráveis.

É necessário enfatizar, segundo o art. 18, do Decreto $\mathbf{n}^{\mathbf{0}} \mathbf{4 . 0 8 5}$, de 15 de janeiro de 2002 (que promulga a Convenção $\mathrm{n}^{\mathrm{o}} 174$ da OIT e a Recomendação $\mathrm{n}^{\mathrm{o}} 181$ sobre a Prevenção de Acidentes Industriais Maiores) que: "a autoridade competente deverá dispor de pessoal devidamente treinado e qualificado que tenha a competência adequada e com o apoio técnico e profissional suficiente para inspecionar, investigar [fiscalizar], avaliar e assessorar assuntos tratados nesta Convenção e garantir a conformidade com a legislação nacional". Atuação do Estado no licenciamento das atividades da Hydro mostrou-se em total desconformidade com esse decreto.

Quanto à Lei $\mathrm{n}^{\mathrm{o}}$ 12.334, de 20 de setembro de 2010, que estabelece a Política Nacional de Segurança de Barragens (PNSB), destacamos outra contradição. Nela, fica determinado que o controle de barragens pelo poder público deve se dar com base na "fiscalização, orientação e correção das ações de segurança", a partir do Plano de Segurança da Barragem. Os procedimentos seguem com a apresentação de Relatórios de Segurança de Barragens e relatórios decorrentes das inspeções de segurança, além de revisões periódicas de segurança.

O relatório de segurança de barragens de 2015 acusa a ausência de qualquer equipe de fiscalização da SEMAS (ANA, 2016), o que contraria as exigências quanto ao controle que deve ser exercido pela secretaria. Sobre isso, o relatório de 2017 da ANA esclarece que "como parte integrante da gestão da segurança de barragens no Estado do Pará, a SEMAS está em fase de planejamento para iniciar as fiscalizações das barragens cadastradas em seu banco de dados" (ANA, 2017). Ou seja, mesmo que existam barragens há mais de 30 anos no estado do Pará, até o 2017 não houve qualquer ação 
efetiva da SEMAS quanto a exigência de fiscalizações.

A não fiscalização é demonstrada indiretamente pela Hydro Alunorte ao assinalar que o duto irregular/clandestino construído para escoamento de rejeitos fora construído e operava durante o início da construção de barragem de rejeitos:

Este duto foi utilizado originalmente durante a construção de sua respectiva área na Hydro Alunorte, mas nunca mais foi utilizado desde então. Ao ser detectado durante uma vistoria, a Hydro selou imediatamente o duto. Quando a construção foi concluída, a entrada do duto foi fechada com concreto e aí esteve inativo por anos, sem ser utilizado. Durante as chuvas fortes nos dias 16 e 17 de fevereiro, constatou-se que o duto não estava suficientemente selado. $\mathrm{O}$ volume da água no solo subiu e fez com que a água das chuvas entrasse no duto através de rachas existentes no concreto. Ao ser detectado durante uma vistoria, a Hydro selou imediatamente $o$ duto de novo. (https://www.hydro.com/pt-BR/a-hydro-no-brasil/Imprensa/Noticias/2018/alunorte/dutoabandonado-e-licenca-ambiental-da-hydro-alunorte/).

Segundo o relatório $n^{\circ}$ 003/2018 (Processo $n^{\circ}$ : 010/2018), do Instituto Evandro Chagas (IEC), havia dois canais de lançamento irregular de efluentes. O primeiro denominado de canal antigo ou canal auxiliar, e o segundo denominado de canal de efluentes de cinzas.

\section{AS IRREGULARIDADES E VIOLAÇÕES DAS LICENÇAS AMBIENTAIS DA HYDRO ALUNORTE}

Destaca-se que os projetos das barragens de rejeitos (DRS1 e DRS2) da Hydro Alunorte possuíam licença de instalação, emitida pela SEMAS para o DRS1 e o DRS 2. Todavia, para a construção da DRS 2 não foram realizados Estudos de Impacto Ambiental específicos. A argumentação da não elaboração do EIA era que DRS 2 já estava inserida no EIA da DRS1, que integrava os primeiros estudos da fábrica, que datam o ano de 1986. Todavia, o EIA/RIMA da DRS1 não se encontra integralmente disponível no site oficial da SEMAS e nem anexado ao arquivo do processo de licenciamento ambiental.

A abordagem do licenciamento ambiental pautou-se, portanto, na falta de conhecimento sobre os reais efeitos de abertura de um novo depósito de rejeitos. Com isso, reitera-se o "entendimento de que os danos sociais e ambientais da mineração tenderiam a se restringir à mudança da paisagem e ao local da mina" (MILANEZ, 2017b, p. 93), desconsiderando o que significa a acumulação dessas ações sobre o meio ambiente e as populações.

Cabe pontuar também que a Resolução CONAMA, nº 001, de 23 de janeiro de 1986, define que, tanto o licenciamento de complexos e unidades industriais, quanto distritos industriais e zonas estritamente industriais, dependem de elaboração de estudo de impacto ambiental e respectivo Relatório de Impacto Ambiental (RIMA), que devem ser submetidos à aprovação do órgão estadual competente, e do IBAMA em caráter supletivo, fato este absolutamente ignorado em todo o licenciamento da Alunorte.

Entendemos, em acordo com Singulane (2011), que as ampliações e mudanças nos planos e projetos originais da Alunorte/Hydro e da sua inserção na Zona Industrial de Barcarena devem gerar estudos e relatórios de impacto ambiental:

[...] as hipóteses estabelecidas pelo rol da Resolução CONAMA 001/86 (acima citada), ou de outras leis ou regimentos, são regidas pelo princípio da obrigatoriedade, através do qual tem o dever Órgão Público, e não apenas a faculdade de elaborar o EIA, dessa forma, o rol é exemplificativo no sentido da somatória das atividades, porém é considerada obrigatória a elaboração do estudo do impacto ambiental á estes relacionados. Nestes casos, o Poder Público está vinculado, não podendo apresentar razão para a dispensa do estudo e do relatório, sob pena de incorrer na pratica de 
prevaricação, além de responsabilidade civil e administrativa do agente envolvido [grifo nosso].

Os dados concernentes ao licenciamento, como a obra e os impactos da DRS 2, não foram disponibilizados pela SEMAS à sociedade e nem submetidos a audiências públicas no município de Barcarena. Muito menos há estudos para a identificação de impactos sinérgicos mais amplos à região, pois as sucessivas ampliações da Alunorte estão inseridas num contexto histórico de implantação de outras indústrias ao seu redor. Ou seja, um desastre prossegue "ainda mais intenso e com novas nuances de degradação na vida cotidiana dos grupos sociais mais afetados" (VALÊNCIO, 2014b, p. 16), quando associados à atuação de um conjunto de empresas que ignoram a segurança e os direitos humanos.

Essas incoerências e inconsistências contribuíram para adicionar uma variável a mais aos antigos conflitos e tensões entre agentes econômicos, sociais e institucionais, como lideranças, associações, sindicatos, movimentos sociais, comunidades, poder público municipal e agentes empresariais locais com interesses múltiplos (HAZEU, 2015; CARMO, CASTRO, PATRÍCIO, 2015; CARMO, 2017).

Observa-se nesse contexto: i) ausência de debates amplos participativos e deliberativos; ii) a geração de desemprego e/ou empregos precários; iii) conflitos em torno de posse e titulação de terras; iv) limitações em relação ao uso dos recursos naturais coletivos por parte das comunidades tradicionais; v) casos de racismo ambiental e conflitos ambientais; vi) deslocamentos forçados e ameaças de deslocamentos; vi) grilagem de terras; viii) elevados índices de degradação ambiental promovidos por empresas nacionais e internacionais; $x$ ) conflitos/conflitualidades entre familiares e comunidades, além de conflitos/conflitualidades entre comunidades, lideranças, associações e sindicatos; e, xi) violação de direitos humanos e étnicos de povos tradicionais (indígenas, quilombolas e ribeirinhos).

Quanto à violação de direitos humanos, tal prática é reiterada no campo da indústria extrativa mineral (MILANEZ; SANTOS; PINTO, 2018) em relação aos povos tradicionais de Barcarena, em virtude da supressão dos direitos territoriais de propriedade ancestral e comunal destes povos sobre suas terras (BELTRÃO et al., 2014). Atualmente, há cinco comunidades quilombolas com certificação da Fundação Palmares: São Sebastião de Burajuba, Sítio Conceição, Sítio Cupuaçu/Boa Vista, Sítio São João, Gibrié do São Lourenço (MOVIMENTO BARCARENA LIVRE, 2016); além de muitas comunidades tradicionais que ainda não foram reconhecidas formalmente, como Curuperé, Canaã, Maricá, Ilha São João, Acuí, Pramajó/Peteca, Dom Manoel e Bairro Industrial (LAUDO TÉCNICO No 001/2016) (SILVA, 2016).

Isso revela um processo antidemocrático/não participativo (sem publicidade e debate), com uma assimetria bem marcada entre papéis e tomadas de decisões (principalmente no tange o envolvimento da sociedade), configurando um projeto "hegemônico e autoritário" (CASTRO, 2012, p. 50 -1) de quem conduziu o licenciamento (o Estado) e de quem opera as atividades industriais (nesse caso, a Hydro Alunorte).

O licenciamento do DRS 2 iguala-se em precariedade ao da barragem do Fundão (em Mariana, da empresa Samarco), que, segundo Santos e Milanez (2018), perfez-se de forma fragmentada, em pedaços, orientada ao subdimensionamento dos impactos e do número de atingidos, compreendendo-os separadamente e como especificidades de cada projeto ou obra. Não houve ou não foi considerado o "processo de avaliação de Impacto Ambiental"”, que, no caso do DRS 2 deu-se como mera formalidade para obtenção de licença ambiental. Isso inclui a avaliação sobre os sistemáticos casos de transbordamentos e/ou vazamentos (2005 e 2009) que não foram considerados.

\footnotetext{
${ }^{9}$ Segundo Bursztyn (1994) abrange amplo leque de atividades e ações que precedem e prossegue o processo de avaliação ambiental, isto é, o licenciamento ambiental.
} 
Essa perspectiva aponta que os "impactos são limitados no tempo" (MILANEZ, 2017b, p. 94); contudo, segundo Milanez (2017b, p. 94): “Os impactos socioambientais da mineração não são simples, nem espacialmente limitados, muito menos temporalmente restritos. Na verdade, muitos deles são ecologicamente complexos, espacialmente amplos e, por serem irreversíveis, temporalmente permanentes".

Esses impactos são "temporalmente permanentes" que houve inúmeras denúncias e alertas realizados pela sociedade civil organizada e as universidades. O movimento Barcarena Livre, por exemplo, vinha realizando denúncias, principalmente em parceria com a Academia, em 2016. Denúncias ocorridas no I Seminário Desastres da Mineração: Pará e Minas, ocorrido dia 25 e 26 de Fevereiro de 2016 (na Universidade Federal do Pará/UFPA), cujo objetivo foi debater a mineração na Amazônia e no Brasil e seu papel no mundo atual, principalmente na produção de desigualdades, riscos, violências e expropriações. Ainda em 2016 (em maio) já no II Seminário Desastres da Mineração: Barcarena Brasi $^{10}$ foram denunciados a barragem de rejeitos, que poderia transbordar ou romper, causando uma série de problemas ambientais e sociais à cidade, às comunidades e aos ecossistemas. Em síntese era a apresentação-divulgação de um "desastre a espreita" (VALENCIO, 2014a, p. 277).

Os desastres de grande proporção como os de 2009 e 2018 tiveram uma participação de grandes agentes políticos e econômicos: o Estado e a multinacional, Hydro Alunorte. Por parte do Estado sua corresponsabilidade se materializa: i) com um "licenciamento flash" e desburocratizado; ii) com o apego à política desenvolvimentista não-democrática; iii) por meio da concessão de isenções fiscais; e, iv) através da captura de créditos, compra da dívida pública e investimentos, por meio de investimentos externos diretos e o "desembarque" de outros agentes econômicos (e fictícios) ligados direta ou indiretamente ao setor da mineração.

Nossa afirmação converge com o trabalho de Marshall (2017) ao analisar os desastres de rompimentos de barragem rejeitos, no Brasil e no Canadá:

Tanto no Brasil quanto no Canadá, os governos federais e provincial/estadual são ideologicamente alinhados com a ordem neoliberal, que tem prevalecido globalmente desde meados dos anos 1970. Os mantras neoliberais de privatização, desregulação, redução do tamanho do Estado e cortes nos investimentos sociais são considerados como única forma se implantar políticas econômicas (MARSHALL, 2015). Da mesma forma, governos tanto no Canadá como no Brasil vêm buscando ativamente atrair investidores privados, nacionais e estrangeiros, como condição para o crescimento econômico e criação de empregos (MARSHALL, 2017, p. 31).

Ainda para Marshall (2017):

Em ambos os países, os governos já tinham flexibilizado consideravelmente requisitos de licenciamento e monitoramento ambiental. Mesmo assim, representantes do setor mineral ainda realizavam campanhas de lobby contínuas por mais desregulação, argumentando que procedimentos burocráticos comprometiam sua eficiência e produtividade (MARSHALL, 2017, p. 31).

Ao mesmo tempo em que houve a redução da supervisão pública (fiscalização, monitoramento) das operações de extração mineral e da barragem de rejeitos, houve também um fator fiscal que se

\footnotetext{
${ }^{10}$ Os seminários foram organizados e realizados pelo GETTAM/NAEA/UFPA (Grupo de Pesquisa sobre Estado, Território, Trabalho e Mercados Globalizados (GETTAM) do Núcleo de Altos Estudos Amazônicos) (Grupo sob Coordenação da Prof ${ }^{a}$ Edna Castro), LABPSAM/ICSA/UFPA (Laboratório de Pesquisa e Práticas Sociais da Amazônia do Instituto de Ciências Sociais Aplicadas (Grupo sob Coordenação da Sandra Helena Cruz), IBASE (Instituto Brasileiro de Análises Sociais e Econômicas) e Associações e Comunidades de Barcarena e o Movimento Barcarena Livre.
} 
adiciona à produção do desastre em Barcarena. Em 2015, a Resolução SEFA n ${ }^{\circ} 14$ de 10/07/2015 concedeu "perdão" tributário às operações da cadeia integrada de alumínio, por quinze anos, com um perdão de R \$ 7,5 bilhões de impostos que não serão pagos, entre 2015 a 2030.

No caso da Hydro Alunorte, o aumento da produtividade (e expansão de refinarias e exploração de outras áreas minerárias) ocorre em virtude da diminuição nos preços das commodities, sobretudo, as minerais, nos anos 2011 e 2012. Assim, precisava-se extrair, expandir e exportar mais, em busca de maiores lucros ou a recuperação de taxas médias de lucros mais significativos, e, consequentemente atender acionistas cada vez mais exigentes no que tange a valorização de ações e ganhos empresariais. Cabe destacar que já havia um processo já bastante intensificado de extração e expansão, devido o boom dos preços, antes de 2011.

Esse cenário instigou e promoveu outras expansões que ocorreram nos projetos da mineradora Samarco (Vale e BHP Billiton)/Mariana-Minas Gerais e da Hydro Alunorte/Barcarena-Pará.

Segundo Picanço (2017, p. 141):

Nos anos de 2013 e 2014 uma grave crise financeira atingiu a maior refinaria de Alumina do Mundo, a Hydro Alunorte, fazendo com que a empresa enfrentasse grande prejuízo nestes anos. No final de 2013, uma grande reação foi iniciada com a reestruturação do corpo gerencial e da empresa como um todo. A reestruturação da empresa foi coordenada tomando como base os princípios do Lean manufacture, para este caso, um Sistema de gestão próprio conhecido como BABS (Bauxite \& Alumina Business System), porém desenvolvido na Noruega a partir da implementação dos princípios do Lean manufacture nas fábricas de Alumínio da Hydro (AMBS Aluminium Metal Business System).

A Hydro Alunorte na busca de maiores lucros ou a recuperação de lucros e o aumento do preço das ações concentrou seus esforços em provar que não houve transbordamento, que não havia dutos clandestinos e também que não houve contaminação; quando deveria listar e realizar propostas tecnológicas e sociais como forma contornar ou minimizar os danos e degradações. No caso do transbordamento da barragem de rejeitos, a Hydro Alunorte, já sabia que o DRS1 tinha vida útil até 2016, como consta no relatório, protocolado e carimbado pela SEMAS, no dia 28/05/2013 (Figura 2) e no Memorial Descritivo de Estação de Tratamento de Efluentes Industriais, protocolado na SEMAS, no dia 19/11/2014 (Figura 3). Contudo, mesmo após 2016, os resíduos continuaram a ser despejados no referido depósito.

Figura 2 - Estudo para Expansão do deposito - DRS 2 protocolado e carimbado pela SEMAS/PA

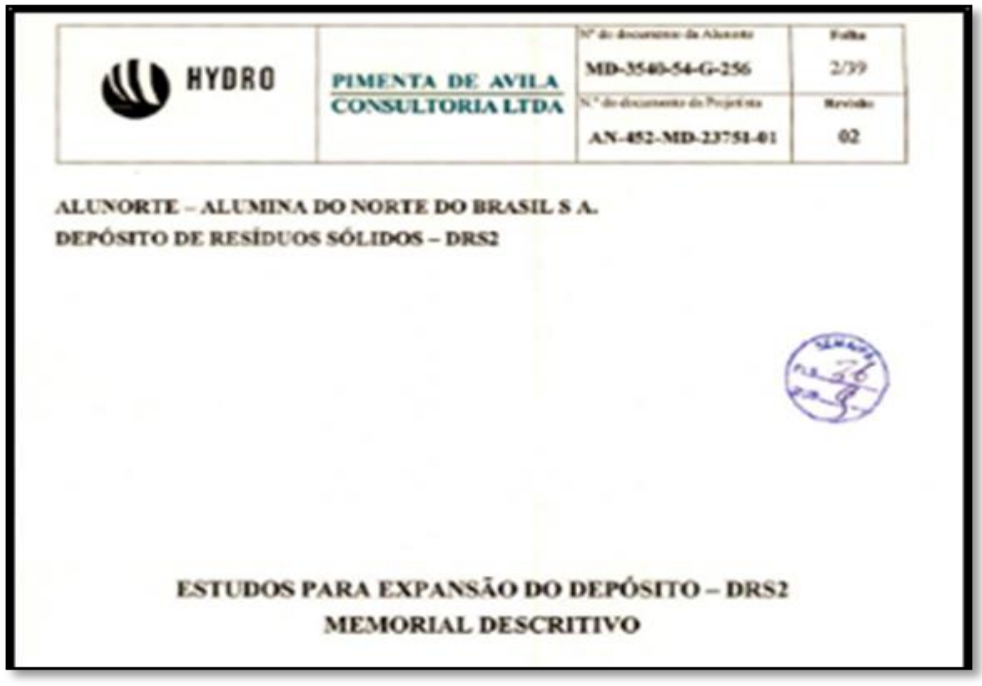


Neste estodo coocluiu-se na epoca por expandir a direa denominada de D1 (DRS1: DRS atual + CL.1/2/3), o qual encontra-se $\mathrm{cm}$ operacalo, com previsbo de vida tail ate meados de 2016. Posteriormente seria ocupado o depósito D2 (DRS2), numa lica cntre a PA-481 e a margem esquerda do Igarapt Tauh, no qual se insere o estudo referente a este memocial deseritivo.

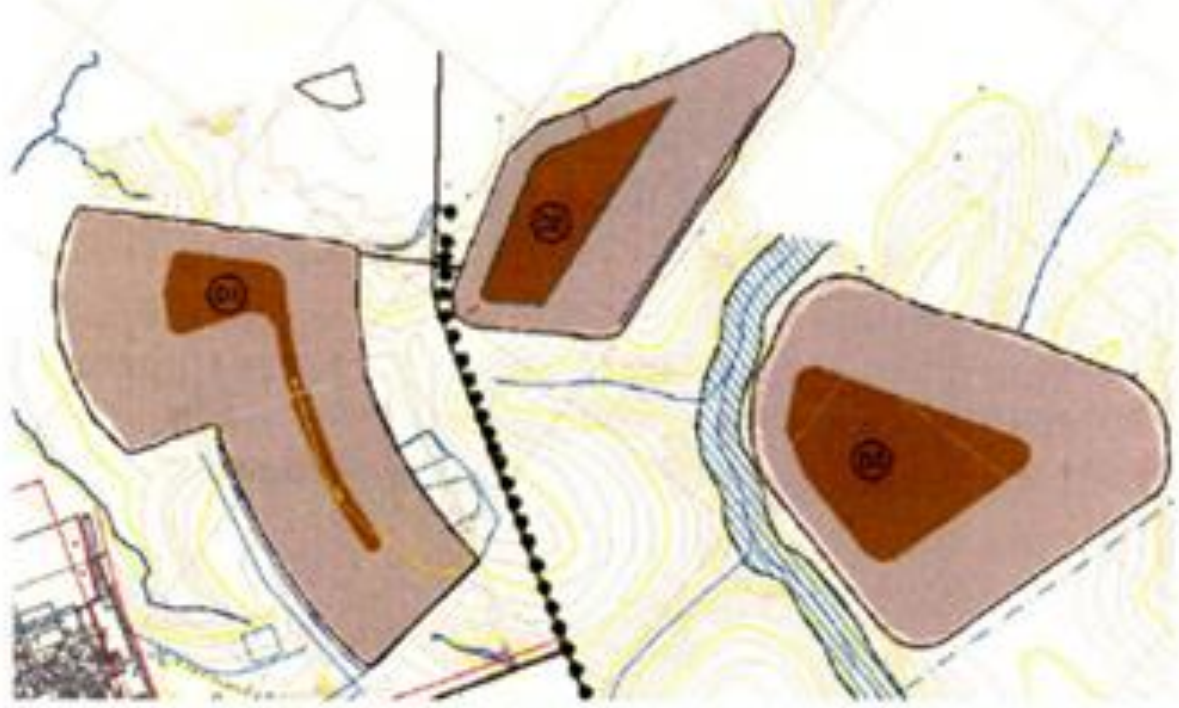

Figura 1 - Posiçlo do DRS2 a sul da PA-481 - Alternativa 6 do Estudo de Viabilidade

Figura 3 - Memorial Descritivo de Estação de Tratamento de Efluentes Industriais (ETEI)

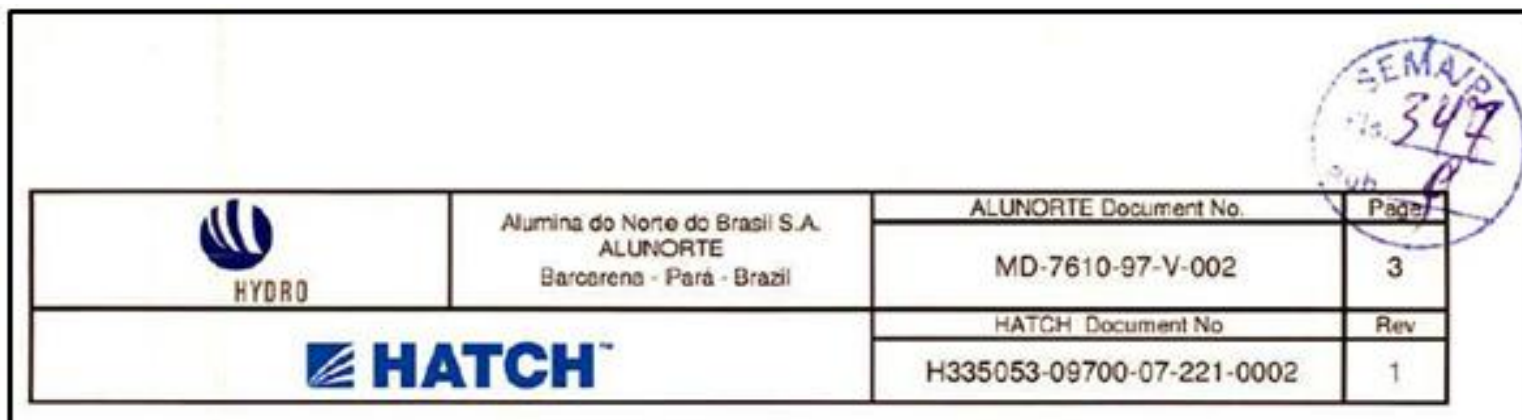

\section{Introdução}

Este Memorial Descritivo tem como objetivo apresentar a descriçāo da Ampliaçảo da Estaçāo de Tratamento de Efluentes Industriais - Área $82 \mathrm{E}$ à Secretaria de Estado do Meio Ambiente do Pará SEMA, e subsidiar o Licenciamento Ambiental desta ampliaçăo.

A ampliação da Estação de Tratamento de Elluentes Industriais (ETEI) será necessária devido a ampliaçăo da área de deposiçăo de residuo de bauxita e consequente aumento da contŕbuiçầo de águas pluviais.

O residuo de bauxita passa primeiramente por um processo de filtraçăo, reduz/lio seu teor caustico e a quantidade de água, podendo ser transportado e empilhado no DRS. Atualmente, o DRS-1 encontra-se próximo do seu limite de estocagem, sendo necessário o inicio dos trabalhos para ampliaçấo da área do dopósito, referente ao DRS-2, cujo licenciamento ambiental já fora abordado em documentos anteriores.

A água da chuva ao entrar em contato com o residuo de bauxita empilhado no DRS lixivia este material, tornando a água imprópria para lançamento em corpos d'água devido ao aumento do pH e da furbidez.

Segundo o relatório da Hydro a geração anual de resíduos (lama vermelha) na base seca seria de 4.702.970 t/ano e de resíduo úmido 7.838.283 t, correspondendo 13.563 t/dia (ano base: 2013). A LO concedida pela SEMAS em 05/08/2014 apontava a produção de 6.375.000 t/ano de rejeitos. 
Diante das evidências de todos esses problemas, era obrigação do poder público, de acordo com o Decreto $\mathbf{n}^{0}$ 4.085, de 15 de janeiro de 2002 (que promulga a Convenção $\mathrm{n}^{\mathrm{o}} 174$ da OIT e a Recomendação $n^{\circ} 181$ sobre a Prevenção de Acidentes Industriais Maiores):

Art. 4 - Todo Estado Membro [o Estado-nação] deverá formular, adotar e revisar periodicamente, considerando a legislação, as condições e a prática nacionais, e em consulta com as organizações mais representativas de empregadores e de trabalhadores, e com outras partes interessadas que possam ser afetadas, uma política nacional coerente relativa à proteção dos trabalhadores, da população e do meio ambiente, contra os riscos de acidentes maiores;

Art. 5 - A autoridade competente ou um organismo aprovado ou reconhecido pela autoridade competente deverá realizar uma prévia consulta com as organizações mais representativas de empregadores e de trabalhadores e com outras partes interessadas que possam ser afetadas, estabelecer um sistema para a identificação das instalações expostas a riscos de acidentes maiores segundo se definem no artigo $3, \mathrm{c}$ ), baseado numa lista de substâncias perigosas ou de categorias de substâncias perigosas, ou de ambas, que inclua suas quantidades limites respectivas, de acordo com a legislação nacional ou com as normas internacionais.

Quanto às obrigações das empresas, esse mesmo Decreto destaca a necessidade de:

- medidas técnicas que compreendam o projeto, os sistemas de segurança, a construção, a escolha de substâncias químicas, o funcionamento, a manutenção e a inspeção sistemática da instalação;

- informar sobre os possíveis acidentes e os planos de emergência locais, às autoridades e aos organismos encarregados de estabelecer os planos e procedimentos de emergência para proteger à população e ao meio ambiente na parte externa da instalação;

- medidas destinadas a limitar as consequências de um acidente maior (Art. 9);

Contrariando todas as orientações sobre sua atuação, a Hydro não assumiu sua responsabilidade do desastre, mesmo diante das comprovações apresentadas pelo Instituto Evandro Chagas (IEC) no Relatório 003/2018/ Processo No: 010/2018 (publicado em 28/03/2018), intitulado “Avaliação preliminar dos impactos ambientais referente ao transbordo e lançamentos irregulares de efluentes de lama vermelha na cidade de Barcarena, estado do Pará". Assim descreve e constata o relatório:

Nos efluentes encontrados na área externa a tubulação de cimento da DRS1 e que circulavam em vala a céu aberto na área do SAMP45, ambos no dia 27/02/2018, foram encontrados níveis de 40.219,04 e 88.253,30 $\mu$ g.L-1, respectivamente, resultados que reforçam a possibilidade de vazamentos contínuos de efluentes para a bacia do rio Murucupi a partir fissuras na tubulação da DRS1, pois foi observado que estas são duas tubulações de cimento que passam em área próximo a floresta e a cerca de $90 \mathrm{~m}$ de distâncias das nascentes deste rio. Estes resultados também mostram que os efluentes que circulavam pela área da SAMP45 também apresentavam teores de alumínio dissolvido bastante elevados, evidenciando que estes sempre deveriam passar por uma estação de tratamento de efluentes (ETE) antes de serem lançados no ambiente. Vale ressaltar que nesse dia ocorriam chuvas relativamente fracas e pouco duradouras, porém era alta a vazão desses efluentes na vala da SAMP45, observação que coaduna com as imagens de inundação e transbordo nessa área no dia 17/02/2018.(p. 44).

É importante frisar de que no processo protocolado na SEMAS, n. 2010/19476, de 26/07/2010, a empresa solicita a "Outorga para diluição de lançamento de efluentes", no município de Barcarena. Efluentes que só poderiam ser lançados após tratamento, e que mesmo tratados, a SEMAS tinha o compromisso de fiscalizar e monitorar esse processo. Todavia, a SEMAS respondera que não era sua 
incumbência outorgas dessa natureza em rios sob dominialidade federal. Em outras palavras, havia um conhecimento da SEMAS (o Estado) acerca do despejo irregular da Hydro, já que ele fora formalmente solicitado à secretaria.

Tais situações evidenciam que essas práticas seriam inerentes ao setor mineral no sentido de proteger a imagem da empresa e do setor, já que um desastre socioambiental implicaria em efeito em cadeia reverberando na volatilidade negativa dos preços dos recursos minerais e preço dos ganhos da empresa e consequentemente de seus parceiros comerciais. Isso construiu uma rede violações de cunho jurídico no que tange a Decreto $\mathbf{n}^{\mathbf{0}} \mathbf{4 . 0 8 5}$, de 15 de janeiro de 2002, que orienta:

Art. 13: Os empregadores deverão informar à autoridade competente e aos demais órgãos designados para esse fim, tão logo um acidente ocorra.

Art. 14: Após um acidente maior, os empregadores deverão, dentro de um prazo estabelecido previamente, apresentar à autoridade competente um relatório detalhado no qual sejam analisadas as causas do acidente e sejam indicadas suas consequências locais, assim como todas as medidas adotadas para atenuar seus efeitos.

Art. 15: Considerando a informação fornecida pelo empregador, a autoridade competente deverá garantir que os procedimentos e planos de emergência que contêm as condições para proteção da população e do meio ambiente fora do local onde estiver situada cada instalação exposta a riscos de acidentes maiores sejam estabelecidos e atualizados em intervalos apropriados e coordenados com autoridades e organismos relevantes.

As determinações à empresa e ao Estado deveriam constituir um gerenciamento social e ambiental compartilhado (JØRGENSEN; MILANEZ, 2017), isto é, um sistema de gestão harmanônico/sinergético. No entanto, a responsabilidade dos erros que levaram ao desastre foram transferidos à ação natural das chuvas da região, conforme expressa o discurso da empresa e do Estado (na figura do governador do estado do Pará):

[Informativo no site da Hydro Alunorte]: Durante os dias 16 e 17 de fevereiro de 2018, a cidade de Barcarena foi atingida por chuvas extremas, alagando a região. A mesma chuva atingiu a Alunorte. Foram registrados mais de $200 \mathrm{~mm}$ de chuvas no período de 12 horas. Como grande parte de Barcarena não é asfaltada, a água das chuvas adquiriu coloração avermelhada, característica do solo da região. A Hydro também investigou a situação. Além de uma força-tarefa interna, a empresa contratou a consultoria ambiental SGW Services, que desenvolveram estudos para estabelecer e verificar os fatos e circunstâncias relacionados com as chuvas. Os resultados apresentados em 9 de abril de 2018 constataram que não houve rompimento, transbordo ou vazamento dos depósitos de resíduos sólidos de bauxita na Alunorte. (https://hydro.com/pt-BR/a-hydro-no brasil/Imprensa/Situacao-das-operacoes-no-Para/entenda-o-fato/as-chuvas-e-impactosem-barcarena-e-na-alunorte/).

Vale ressaltar que no mês de fevereiro choveu $696 \mathrm{~mm}$ e, no período de 16 à 22 de fevereiro, $453 \mathrm{~mm}$. O que isso significa? Significa que choveu bem mais que a média para o período nos últimos 30 anos, que foi de 370 (Governador do Pará - Simão Jatene, dia 26 de fevereiro de 2018) (https://www.diarioonline.com.br/noticias/para/noticia489432-governo-jatene-foi-avisado-dos-riscos-de-vazamento-na-hydro.html).

Há uma convergência de interesses a ações entre empresa e Estado de "processo de homologação ambiental" (MILANEZ; SANTOS, 2018), com (gradual) institucionalização e padronização das práticas e discurso coesos, sem desencontros e convergentes argumentativamente, que, por exemplo, acionam a estratégia de responsabilizar a taxa pluviométrica ocorrida naquele período. No entanto, o volume elevado de chuvas na região é de conhecimento geral e também da Hydro e da SEMAS. A elevada capacidade técnica e tecnológica das bombas de sucção que a Hydro possui em caso de excessos de chuva revela esse conhecimento. 
Com isso, construiu-se a narrativa que os vazamentos constituem "acidentes normais ou desastres naturais" (VALENCIO, 2015), que podem ser igualados às inundações e terremotos (QUARANTELLI, 2015, p. 41). Com isso acabam sendo criado um evento episódico que congela a complexidade social e a processsualidade histórica, política e econômica da construção do desastre, e invizibiliza as estruturas e forças de poder que são contribuidoras significativas na produção de desastres (VALÊNCIO, 2011, 2014a, 2014b).

A SEMAS em fiscalização no dia 17/02/2018 insistia que não havia ocorrido transbordamento/vazamento na barragem de rejeitos (Relatório de fiscalização: REF-1-S/18-03-00007), na comunidade Bom Futuro, porém (contraditoriamente) identifica efluentes pluvias para área de floresta, algo já constatado pela Secretaria de Meio Ambiente e Desenvolvimento Econômico de Barcarena, pelo Termo de Constatação nº6/2018/DFA lavrado no dia 17/02/2018 acerca de tubulação que lançava efluentes líquidos empossado na área 45 da empresa. Porém, o REF-1-S/18-03-00007 é inserido no auto de infração da SEMAS acerca dessa tubulação clandestina, que foi lavrado no dia 07 de março de 2018.

O "evento natural", isto é, o excesso de chuva nos dias 16 e 17 de fevereiro de 2018, foi peça argumentativa-central, uma criação discursiva de pseudoverdade. Os dados de 1977 a 2006 da Companhia de Pesquisa de Recursos Minerais (CPRM) revelam isso quando confrontados com os dados disponíveis do Centro de Previsão de Tempo e Estudos Climáticos (CPTEC) ${ }^{11}$, do Instituto Nacional de Pesquisas Espaciais (INPE), que nos permitem afirmar que as chuvas que ocorreram nos dias 16 e 17 de fevereiro em Barcarena, estão dentro dos padrões históricos e que, por isso, não podem ser "culpabilizadas" pelo desastre. Suas causas são relacionadas à forma mesmo como a empresa opera sua produção e toda poluição decorrente dela.

Além disso, o processo carece ainda da apresentação dos seguintes documentos:

i) um "Plano de Prevenção de Controle Desastres" (segurança de barragem);

ii) Plano de Gestão de Risco;

iii) um "Sistema de Alerta de Eventos Críticos", em caso de desastre; e,

iv) um sistema de alerta dentro empresa (para os trabalhadores) e sua comunicação com redes defesa civil da cidade e de órgão públicos, municipal e estadual.

Isso revela as consecutivas irregularidades do processo tocado pela SEMAS que não realizou cobranças acerca da criação dos sistemas mencionados. Isso evidencia, segundo Santos e Milanez (2018) que há um processo de "privatização da regulação mineral", com a suposta mudança de um modelo 'fraco' para a autorregulação, de auto-compromisso, de iniciativas voluntárias por parte das empresas.

Após o desastre, essa autoregulação que a SEMAS adotava começou a ruir. Com pressões midiáticas, movimentos sociais e políticos, a SEMAS iniciou suas ações, com vários autos de infração (sete autos) $^{12}$, apontando a disposição inadequada de material sedimentar, oriundo de obras ainda de implantação da barragem de rejeitos. Porém, não houve embargado ou cancelamento das licenças ambientais concedidas ao DRS 2.

Os desastres não possuem espacialidade-temporalidade demarcada, mas seus nexos sociais explicativos, no geral, apontam para responsabilidades mútuas, vislumbradas:

1) Na ausência de fiscalização e na não elaboração do EIA/RIMA;

2) No não respeito à Lei $n^{\circ}$ 12.334, de 20 de setembro de 2010, que estabelece a Política Nacional de Segurança de Barragens acerca "controle de barragens pelo poder público, com base na fiscalização, orientação e correção das ações de segurança", pautado na cobrança de um Plano de

\footnotetext{
${ }^{11}$ Disponível em:

http://www.cprm.gov.br/publique/media/hidrologia/mapas_publicacoes/atlas_pluviometrico_brasil/isoietas_medias_ mensais_1977_2006.pdf e http://clima1.cptec.inpe.br/monitoramentobrasil/pt.

${ }^{12}$ Vide os autos de infração em emitido pela SEMAS em: https://www.semas.pa.gov.br/2018/02/24/documentos-2/.
} 
3) Segurança da Barragem, com Relatório de Segurança de Barragens, relatórios das inspeções de segurança e revisões periódicas de segurança e áreas de contenção e inspeções diárias;

4) Licenciamento obscuro e antidemocrático, pois não ocorreram audiências públicas no município de Barcarena, com a apresentação da identificação de impactos sinérgicos. Portanto, houve uma carência de transparência no pré-desastre (com a concessão da licença) e no pós-desastre (com processos de desinformação acionados em torno dos níveis de contaminação da água potável, poços artesianos e qualidade dos rios);

5) No caso do transbordamento/vazamento, a Hydro Alunorte, já sabia ou tinha consciência que tempo útil dos depósitos resíduos tinham vida útil até 2016 (capacidade de estoque,) assim como a SEMAS quando recebeu os documentos que pautaram a concessão da licença de instalação da barragem de rejeitos, a DRS2;

6) O não cumprimento por parte do Estado das obrigações gerais de respeito e garantia dos direitos humanos a grupos vulneráveis, bem como o não monitoramento semanal e/ou mensal dos rios e igarapés impactados como também as pessoas e comunidades "atingidas" (Bom Futuro, Jardim dos Cabanos, Burajuba e Vila Nova);

\section{CONSIDERAÇÕES FINAIS}

Ao longo do artigo foi analisado criticamente o processo de Licenciamento Ambiental (LA) da barragem de rejeitos da Hydro Alunorte, em Barcarena, no estado do Pará e como ele contribuiu na produção de "riscos e desastres industriais ou socioambientais". Para tanto, questionamos que os desastres foram construídos, a partir das inúmeras irregularidades e incoerências. A tentativa foi desenrolar o novelo do LA da Hydro Alunorte, relacionando-o diretamente aos desastres que vem se repetindo na indústria extrativa mineral, como no caso de Mariana e Brumadinho. O desastre, neste sentido, não se constitui simplesmente um elemento isolado no espaço-tempo, ela aponta a relação estrutural entre eventos de rompimento de barragens de rejeitos e os ciclos econômicos da mineração (WANDERLEY, GONÇALVES; MILANEZ, 2016). Ao mesmo tempo revela-se o jogo de interesses e parcerias entre Estado e mercado/empresas, com “discursos afinados". Portanto, o LA não constitui um elemento técnico e sim componente político contribuinte de desastres.

Por isso, é possível afirmar que os desastres não são advindos de erros e negligências humanas ou falhas em sistemas ou leis, mas são exemplos que indicam que as estruturas de licenciamento, monitoramento e controle ambiental existentes vem sofrendo um "processo de captura regulatória" (MARSHALL, 2017, p. 33) e vem constituindo-se de meras autorizações e não cumprindo todos os ritos exigidos num processo de LA. Sendo assim resultado também: i) de "licenças de permissão" de crimes ambientais a empresas concedidos pelo Estado; ii) apoio do Estado não apenas a concessão de licenças, mas por insuficiência de mecanismos punitivos concretos, mas por discurso legitimatórios e afinados ao sistema viciado da empresa, isto é, de desastres e crimes constantes.

O LA da barragem de rejeitos DRS 1 e principalmente da DRS 2 da Hydro Alunorte seguiu a égide da eficiência e rapidez econômica e institucional, com pouca consideração sobre suas implicações sociais e econômicas, o que contribuiu para a contínua e sistemática exposição aos perigos múltiplos decorrentes das atividades industriais em Barcarena e a intensificação do processo histórico de vulnerabilização.

O estudo constatou inúmeras irregularidades no processo de LA, das três grandes expansões produtivas da Hydro Alunorte: 1) a dispensa de Estudos de Impacto Ambiental; 2) a não-realização de 
fiscalizações e monitoramento das barragens; 3) a não-observância das bases legais, como a PNSB; 4) ações de natureza antidemocrática/não participativa e com violação de direitos humanos. Tais irregularidades contribuíram diretamente para os consecutivos desastres ocorridos nos últimos anos.

\section{REFERÊNCIAS}

ANA - Agência Nacional de Águas. Resolução n. 236, de 30 de janeiro de 2017. Brasília: ANA, 2017.

ANA - Agencia Nacional de Águas. Relatório de segurança de barragens 2017. Brasília: ANA, 2018.

ANM - Agência Nacional de Mineração. Classificação das barragens de mineração brasileiras - data base janeiro/2019. Disponível em: <http://www.anm.gov.br/assuntos/barragens/extracao-sigbm-paraclassificacao-site-atualizada-31jan2019>. Acesso em: 22 fev. 2019.

ANTAQ - Agencia Nacional de Transporte Aquaviários. Estatístico Aquaviário.

<http://web.antaq.gov.br/ANUARIO/>. Acesso em: 06 abr. 2019.

BELTRÃO J. F. et al. Derechos humanos de los grupos vulnerables, 2014. Disponível em: http://www.upf.edu/dhes-alfa/materiales/. Acesso em: 20 jun. 2016.

BURSZTYN, M. A. A.. Gestão ambiental - instrumentos e práticas. Brasília: IBAMA, 1994.

CARMO, E. D. Desastres e tensões em Barcarena à luz de disputas territoriais. In: CASTRO, E. (Org.). Territórios em Transformação: saberes, rupturas e colonialidade. Belém: NAEA, 2017. p. 65-80.

CARMO, E. D.; CASTRO, E.; PATRÍCIO, J. Mineração e neo-extrativismo de commodities e conflitos. Novos Cadernos NAEA, v. 18, n. 3, p. 51-71, 2015.

CASTRO, E. Expansão da Fronteira, megaprojetos de infraestrutura e integração sulamericana. Caderno CRH, v. 25, n. 64, p. 45-61, 2012.

CDP - Companhia Docas do Pará. Estatísticas de 2018. Disponível em:

<https://www.cdp.com.br/estatisticas-2018>. Acesso em: 06 abr. 2019.

COELHO, M. C. N. et al Regiões econômicas mínero-metalúrgicas e os riscos de desastres ambientais das barragens de rejeito no Brasil. Revista da ANPEGE, v.13, n.20, p.83-108, 2017.

G1 PA. Hydro Alunorte, acusada de vazamento de rejeitos, já foi multada em 2009 por esse crime. Disponível em: <https://g1.globo.com/pa/para/noticia/hydro-alunorte-acusada-de-vazamento-de-rejeitosja-foi-multada-em-2009-por-esse-crime.ghtml>. Acesso em: 23 fev. 2019.

GONÇALVES, R. J. A. F.; MILANEZ, B.; WANDERLEY, L. J. Neoextrativismo liberal-conservador: a política mineral e a questão agrária no Governo Temer. Revista OKARA, v.12, n.2, p. 348-395, 2018.

GONÇALVES, R. J. A. F.; MILANEZ, B.; MENDONÇA, M. R. No horizonte, a exaustão. O contexto da mineração no Brasil: mudanças globais, mudanças locais. In: STEFANO, D.; MENDONÇA, M. L. (Orgs). Direitos Humanos no Brasil 2015: relatório da rede social de justiça e direitos humanos. São Paulo: Outras Expressões, 2015. p. 103-112.

HAZEU, M. T. O não-lugar do outro: Sistemas migratórios e transformações sociais em Barcarena. Tese (Doutorado em Desenvolvimento Socioambiental) - Programa de Pós-Graduação em Desenvolvimento Sustentável do Trópico Úmido, Universidade Federal doe Pará, Belém, 2015. 
HAZEU, M. T.; RODRIGUES, J. C. Capitalismo financeirizado e acumulação por despossessão na Amazônia: a mineradora Imerys em Barcarena, Nordeste do Pará. Revista Científica Foz, v. 2, n. 1, p. 86-119, 2019.

JØRGENSEN, M. S.; MILANEZ, B. Downstream management practices of transnational companies in institutionally vulnerable countries: Export and use of hazardous products. Journal of Cleaner Production, v, 140, n. 3, p. 1095-1104, 2017.

MARSHALL, J. Rompimentos de barragens de rejeitos no Brasil e no Canadá: uma análise do comportamento corporativo. Caderno Eletrônico de Ciências Sociais, v. 5, n. 1, p. 27-46, 2017.

MICES - Ministério de Indústria, Comercio Exterior e Serviços. Séries históricas.

$<$ http://www.mdic.gov.br/index. php/comercio-exterior/estatisticas-de-comercio-exterior/serieshistoricas>. Acesso em: 01 dez. 2018

MILANEZ, B. Boom ou bolha? A influência do mercado financeiro sobre o preço do minério de ferro no período 2000- 2016. Versos - Textos para Discussão PoEMAS, v. 1, n. 2, p. 1-18, 2017 a.

MILANEZ, B. Mineração, ambiente e sociedade: impactos complexos e simplificação da legislação.

Boletim Regional, Urbano e Ambiental (IPEA), v. 16, p. 93-101, 2017b.

MILANEZ, B.; COELHO, T.P.; WANDERLEY, L. J. M. O projeto mineral no Governo Temer: menos Estado, mais mercado. Versos - Textos para Discussão PoEMAS, v. 1, n. 2, p. 1-15, 2017.

MILANEZ, B.; SANTOS, R. S. P. Minería en Brasil: problemas, perspectivas y desafíos. In: GANDARILLAS, M. A. (Org.). Extractivismo: nuevos contextos de dominación y resistencias. Cochabamba: CEDIB, 2014. p. 133-154.

MILANEZ, B.; SANTOS, R. S. P.; PINTO, R. Mineração e violações de direitos humanos: uma abordagem construcionista. Homa Publica, v. 1, n.1, p. 130-167, 2018.

MOVIMENTO BARCARENA LIVRE. Barcarena Livre Informa. Belém: IBASE/UFPA/ICSA/NAEA, 2016.

O LIBERAL. Barcarena: Alunorte multada em R\$ 5 mi por vazamento. O Liberal, 30 de abril de 2009.

PICANÇO, F. M. Implantação do sistema de gestão lean em refinaria de alumina e os impactos operacionais na performance da empresa. Revista Gestão Industrial, v. 13, n. 3, 141-159, 2017.

QUARANTELLI, E. L. Uma agenda de pesquisa do século 21 em ciências sociais para os desastres: questões teóricas, metodológicas e empíricas, e suas implementações no campo profissional. O Social em Questão, n. 33, ano 18, p.25-36, 2015.

RODRIGUES, D. Licenças para Degradar? Impactos socioambientais da mineração na América do Sul. Aracaju: EDUNIT, 2016.

SANTOS, R. S. P.; MILANEZ, B. A construção do desastre e a 'privatização' da regulação mineral: Reflexões a partir do caso do vale do Rio Doce. In: ZHOURI, A. (Org.). Mineração: violências e resistências: um campo aberto à produção de conhecimento no Brasil. Marabá: iGuana/ABA, 2018. p. $111-154$

SEDEME - Secretaria de Estado de Desenvolvimento Econômico, Mineração e Energia. Comercio Exterior. <http://sedeme.pa.gov.br/estatistica/>. Acesso em: 18 fev. 2019.

SINGULANE, V. C. Os estudos de impactos ambientais. Âmbito Jurídico, v. 1, 2011. 
SILVA, R. F, A. M. Laudo Técnico No 001/2016 - Seap. Santarém, 22 de julho de 2016. Disponível em: <http://bibliotecadigital.mpf.mp.br/bdmpf/bitstream/handle/11549/153790/laudo_barcarenafinal.pdf?sequ ence $=1$ \&isAllowed=y >. Acesso em: 03 fev. 2019.

SOLSVIK, T.; MOSKWA, W. Hydro compra negócios de alumínio da Vale por US\$4,9 bi. Disponível em: <http://g1.globo.com/economia-e-negocios/noticia/2010/05/hydro-compra-negocios-de-aluminio-davale-por-us49-bi-2.html>. Acesso em: 30 jan. 2019.

SOUZA JUNIOR, T. F. MOREIRA, E. B.; HEINECK, K. S. Barragens de contenção de rejeitos de mineração no Brasil. Holos, v. 5, n. 34, p. 1-39, 2018.

ST-LAURENT, G. P.; BILLON, P. L. Staking claims and shaking hands: Impact and bene!t agreements as a technology of government in the mining sector. The Extractive Industries and Society, v. 2, n. 3, p. 590-602, 2015.

VALÊNCIO, N. A sociologia dos desastres: perspectivas para uma sociedade de direitos. In: Conselho Federal de Psicologia. Psicologia de emergências e desastres na América Latina. Brasília: CFP, 2011. p. 11-30.

VALENCIO, N. Dos desastres recorrentes aos desastres à espreita. In: ZHOURI, A.; VALÊNCIO, N. Formas de matar, de morrer e de resistir: limites da resolução negociada de conflitos ambientais. Belo Horizonte: UFMG, 2014a. p. 277-316.

VALENCIO, N. Desastre como prática sociopolítica de solapamento da segurança humana. In: CARMO, R.; VALENCIO, N. (Orgs). Segurança humana no contexto dos desastres. São Carlos: RiMa, 2014b.

VALENCIO, N. Desastres normais: das raízes aos rumos de uma dinâmica tecnopolítica perversa. In: SIQUEIRA, A. et al (Orgs.). Riscos de Desastres relacionados à água: aplicabilidade de bases conceituais das Ciências Humanas e Sociais para a análise de casos concretos. São Carlos: RiMa, 2015. p. $79-120$.

VALENCIO, N. Cobertura jornalística sobre desastres no Brasil: dimensões sociopolíticas marginalizadas no debate público. Disertaciones - Anuario electrónico de estudios en Comunicación Social, v. 10, n. $2,2017$.

WANDERLEY, L. J. M. Do Boom ao Pós-Boom das commodities: o comportamento do setor mineral no Brasil. Versos - Textos para Discussão PoEMAS, v. 1, n. 1, p. 1-7, 2017.

WANDERLEY, L. J.M.; GONÇALVES R. J. A. F.; MILANEZ, B. Pedras de sangue e choro maculam a vertente: algumas percepções de campo no contexto do desastre da mineração sobre o rio Doce. Élisée, v.5, n.1, p.30-56, 2016.

ZHOURI, A. et al. O desastre do rio doce: entre as políticas de reparação e a gestão das afetações.

ZHOURI, A. et al (Orgs). Mineração: violências e resistências: um campo aberto à produção de conhecimento no Brasil. Marabá: iGuana; ABA, 2018. p. 28-64.

ZHOURI, A.; BOLADOS, P.; CASTRO, E. M. R. Mineração na América do Sul. Neoextrativismo e lutas territoriais. São Paulo: Annablume, 2016. 